\title{
Goodbye. Introducing the new Chief Editors: Peter Sterk and Klaus Rabe
}

\author{
M. Decramer
}

At the end of this year my 3 yrs mandate as a Chief Editor expires. For a variety of reasons I have decided not to seek renewal of my mandate. As a consequence, I will be leaving the European Respiratory Journal $(E R J)$ and the European Respiratory Society (ERS) at the end of the year. It has been a great pleasure to lead this Journal into the new millennium and into an era of novelty. Indeed, in the past 3 yrs we were able to introduce novelty into the $E R J$. There has been major novelty in the technical, logistical field as well as in the contents of the ERJ, which remain of the highest importance for a scientific journal.

In the logistical field we realised on-line distribution and on-line submission. We were the first respiratory journal to introduce a fully developed on-line submission system and were definitely the first journal to shift to full on-line submission at the beginning of this year. This has opened the way to on-line editing and publishing, which led to a complete reorganisation of the Sheffield office. We are indebted to Archie Turnbull, the ERS Executive Manager, Linda Arnold, the Publications Manager, and H. Charlesworth \& Co. Ltd, our printers, who made all of this possible. The end result is that the distribution of the ERJ is now on time and that a high quality product is being delivered at a cost that is only a fraction of what it was before. This is to the benefit of all the members of the ERS since the membership fee may now be used for the Society in other developments. Since I was both Chief Editor and Chairman of the Board of Directors of the ERS Journal Ltd, I also thank the members of the Board for their contributions.

The evolution of the contents has been as remarkable. The impact factor of the $E R J$ has increased from 2.3 at the beginning of my mandate to 2.989 at the end. We have moved from eighth position in the field in 1999 to fifth place in 2001. The evolution of the impact factor of the $E R J$ is shown in figure 1.

We are now on our way to having considerably more scientific impact and the best is yet to come. Indeed, the measures we applied as of January 2000, will only have their full effect in the 2002 impact factor which is to come next year. Nevertheless, we feel that in the future, sustained improvement in the impact factor is required to achieve the ranking in the

Correspondence: M. Decramer, Respiratory Division, University Hospital, Herestraat 49, B-3000 Leuven, Belgium. Fax: 32 16346803. E-mail: marc.decramer@uz.kuleuven.ac.uk respiratory field that a prestigious society such as the ERS deserves. The measures we applied were primarily based on a better selection process of the original papers and an increased proportion of excellent reviews and supplements. The effects of these measures were clearly seen in the number of printed pages, the number of original articles published and the proportion of reviews published, which are summarised in table 1.

All of this did not deter authors from submitting their manuscripts to the $E R J$ as is shown in figure 2. Indeed, the number of submissions increased substantially and in 2002 it is projected to reach the all time high of 1,400 submissions. Despite the increase in the number of submissions our reviewing system worked excellently with verdict times that were reduced from $60+$ days in 1999 to 45 days in 2002 . We are confident that the on-line submission system will allow proper

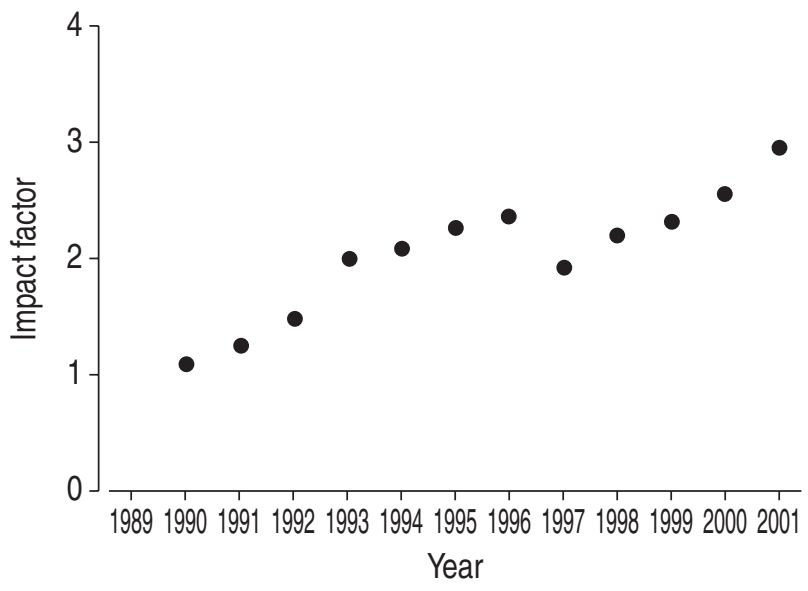

Fig. 1.-Impact factor of the European Respiratory Journal from 1990 to present.

Table 1.-Evolution of the number of printed pages, number of original articles and number of review articles from 1998 to 2001

\begin{tabular}{cccc}
\hline & Printed pages $n$ & Original articles $n$ & Reviews n \\
\hline 1998 & 2973 & 347 & 28 \\
1999 & 3001 & 363 & 20 \\
2000 & 2383 & 273 & 28 \\
2001 & 2451 & 272 & 41 \\
\hline
\end{tabular}




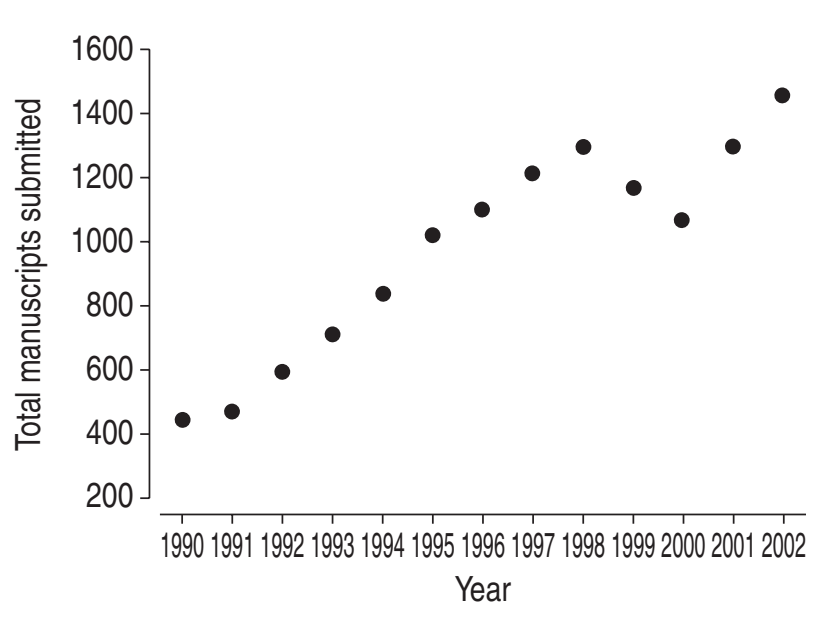

Fig. 2.- Number of articles submitted to the European Respiratory Journal from 1989 to present. Please note an increase in the last years after a fall in 1999 and 2000. The number for 2002 is the projected number based on the first half of the year.

verdicts to be reached in even shorter periods of time. We aim at guaranteeing a verdict to the authors within 40 days of submission. Given the improvements in our performance indicators I feel confident to go: the $E R J$ is in good shape. I would like to take this opportunity to thank all the members of the Editorial Board, the Associate Editors and Assistant Chief Editors for their excellent work, as I was only the mediator of their efforts. A journal is only as good as its Editorial Board and this Board needs to work as a team to achieve common goals. Our frequent meetings certainly built the team spirit and made all the strong individuals act as a team.

The ERS Executive Committee appointed Peter Sterk and Klaus Rabe from Leiden, the Netherlands, as joint Chief Editors. I am somewhat flattered that the Executive Committee, in its wisdom, deemed it necessary to appoint two Chief Editors to replace me. I am confident that with them the ERJ is in safe hands.

Peter Sterk is Professor of Medicine with a Chair endorsed by the Dutch Asthma Foundation at the University of Leiden. He is the head of pulmonary research in his department and is a very well known figure in the asthma world. Peter Sterk has a long lasting record of commitment to the ERS. He has been Assistant Chief Editor for almost $10 \mathrm{yrs}$, he was the head of the Assembly of Allergy and Clinical Immunology from 1994 to 1998, and he was the Chairman of the Scientific Programme Committee of the World Asthma Meeting in Barcelona in 1998. It has been my good fortune to work with him in all of these roles. I remember him as a bright creative personality who always had original and novel proposals for our scientific programme. He has all it takes to move our Journal further ahead.

Klaus Rabe is presently Professor of Pulmonary Medicine and Chairman of the Department of Pneumology in the University of Leiden. He has been active in various fields of Respiratory Medicine in Europe, predominantly asthma, and was also the first European Associate Editor of the American Journal of Respiratory and Critical Care Medicine. He came to pulmonary medicine after an interesting career in Oncology. He is a real personality in European respiratory medicine and I am sure that his appointment as Chief Editor is just the start of a long and successful career in the ERS.

I congratulate my successors with their appointment and I wish them good luck with the European Respiratory Journal in the future. It was a pleasure to serve the scientific community and the readers of this Journal for 3 yrs. I am happy to go at a time when the Journal is doing excellently and I am looking forward to meeting new challenges in the future. Goodbye. 